nor did we mean to imply, that nothing had been done in this area, but rather that the area has been subject to comparatively little investigation when one views it within the context of many other areas of research in animal behavior. Merely citing a few of the studies that have dealt with predatory behavior in reptiles does not refute this argument.

Finally, Burghardt comments on a difference in methodology between his study and our own. Burghardt had difficulty with the freezing method we employed and rejected it because the animals either survived the procedure or turned dark brown. We did encounter similar effects, but only for a small portion of the mealworms. A few mealworms did survive, and a few did turn dark brown; however, most did not, and only those which visually appeared to be their natural color were used as prey. An explanation for the difference in the effectiveness of these procedures may lie in the variable of freezing temperature or in the variables of the genetic composition, variation in natural coloration (in our population, individuals ranged from a light yellow to a medium yellow-brown), or health of the mealworm populations. Another possibility involves the degree to which the dead animals had dried out prior to testing. The animals do, in fact, turn a dark brown when they dry out completely. In this connection, there might have been some sort of a difference between the two procedures, such as different types of containers, number of mealworms thawing in close proximity to one another, humidity and ventilation of the room, etc., which might have affected the speed with which drying occurred.

\section{ASKEW $H$ REFERENCES}

$R .$, MUSIMECI, M. L., \& STEPHAN, L. Effects of prey movement and background on predatory behavior of chameleons. Psychonomic Science, 1970, 20, 171

BURGHARDT, G. Effects of prey size and movement on the feeding behavior of the lizards Anolis carolinensis and Eumeces fasciatus. Copeia, 1964, 576-578.

BURGHARDT, G. A supplementary note on the feeding behavior of the lizard Anolis carolinensis. Psychonomic Science. $1971,23,49$.

\title{
Aftereffects of low intensity UHF radiation*
}

\author{
SUSAN F. KORBEL, KENNETH D. JOHNSON, and PAUL S. ROWLAND \\ University of Arkansas, Fayetteville, Ark. 72701
}

Thirty naive male albino rats were used as Ss in an experiment designed to determine possible behavioral aftereffects of UHF radiation. Fifteen experimental Ss were exposed to UHF of low frequency $(500 \mathrm{MHz})$ and low intensity $(.43-.15 \mathrm{~mW})$ for 38 consecutive days. For Days $39-55$, UHF was not presented to experimental Ss. UHF rats were less active than nonUHF rats and continued to be less active for a short period of time after UHF termination.

Investigations of the effects of ultra-high-frequency (UHF) radio fields, a frequency range from 300 to $3,000 \mathrm{MHz}$, have demonstrated consistent behavioral changes in albino rats. In these investigations (Korbel \& Thompson, 1962, 1965; Korbel \& Fine, 1967; Korbel, 1970), rats were exposed to relatively long-term UHF radiation at low intensities and low frequencies. Radiated rats showed the following behavioral changes relative to the nonradiated rats: (1) hypoactivity, which may be preceded by a short-term period of hy peractivity, (2) greater emotionality, (3) longer latency of recovery from electroconvulsive shock,

* This research was supported in part by a United States Public Health Service grant, No. EC00116-03 (formerly No. RH00530).
(4) longer time to swim a 16-choice water maze, and (5) a differential stress reaction as indicated by adrenal-weight/body-weight ratios. These experiments also point to the importance of two parameters: (1) range of frequency, in that a lower range is more effective in producing behavioral changes than is a higher range, and (2) duration, in that some period of time is required for low-intensity UHF to have an effect on behavior. Although these experiments demonstrate that behavioral changes do occur as a result of UHF radiation, none of them were designed to test for the permanency of the changes. The purpose of the present experiment, therefore, was the investigation of possible residual activity differences subsequent to the termination of the UHF field.

\section{SUBJECTS}

Thirty 22-day-old naive male Sprague-Dawley rats were used as Ss. Ss were assigned randomly to the UHF or nonUHF groups by the use of a table of random numbers.

\section{APPARATUS}

The UHF signal was generated by the use of an amplitude-regulating power supply (General Radio 1263A) and an oscillator with a frequency range from 250 to $920 \mathrm{MHz}$ (General Radio 1209B). A circular discone antenna, resonant on the frequencies used, directed the radio waves to the experimental Ss in their Plexiglas living cages. The living cages were placed in a circle around the antenna so that each $S$ was neither more than $25^{1 / 2}$ in. nor less than $15^{1 / 2}$ in. from the antenna.

Experimental and control groups lived in separate, identical compartments ( $7 \mathrm{ft} 9$ in. $x 5 \mathrm{ft} 9$ in. $x$ $4 \mathrm{ft})$ lined with bronze screening. The living cages for each group were enclosed in a smaller bronze cage $(5 \mathrm{ft}$ $x \quad 5 \mathrm{ft} \quad x \quad 1 \mathrm{ft} 3 \frac{1 / 2}{\mathrm{in}}$.). All bronze shielding in the experimental compartment was grounded through four 6-ft rods which were driven into earth ground. The bronze shielding in the experimental compartment was used to contain the UHF field within the experimental compartment, while the shielding in the control compartment was used only to provide environmental conditions identical to those in the experimental compartment. In order to insure that the power level was held constant and contained within the experimental compartment, daily power level measurements were made with a power meter (Hewlett-Packard 431A).

Activity measurements were made by using an activity platform (Lafayette A-501) connected to an arc suppression impulse counter (Lafayette 5707PS).

Room temperatures were recorded daily from thermometers placed in the experimental compartment, the control compartment, and the behavioral testing room. For any given day, temperatures at these locations did not vary, and the day-to-day temperature was maintained between $74^{\circ}$ and $77^{\circ} \mathrm{F}$ throughout the experiment.

\section{PROCEDURE}

For 38 consecutive days, 15 experimental Ss were exposed to UHF of low frequency $(500 \mathrm{MHz})$ and low intensity $(.43-.15 \mathrm{~mW})$, as measured at the front and back of the living cages, respectively; power level measurements were made inside the cages without the presence of the rat.) Since the experimental Ss were radiated at all times other than the times when behavioral measures were 


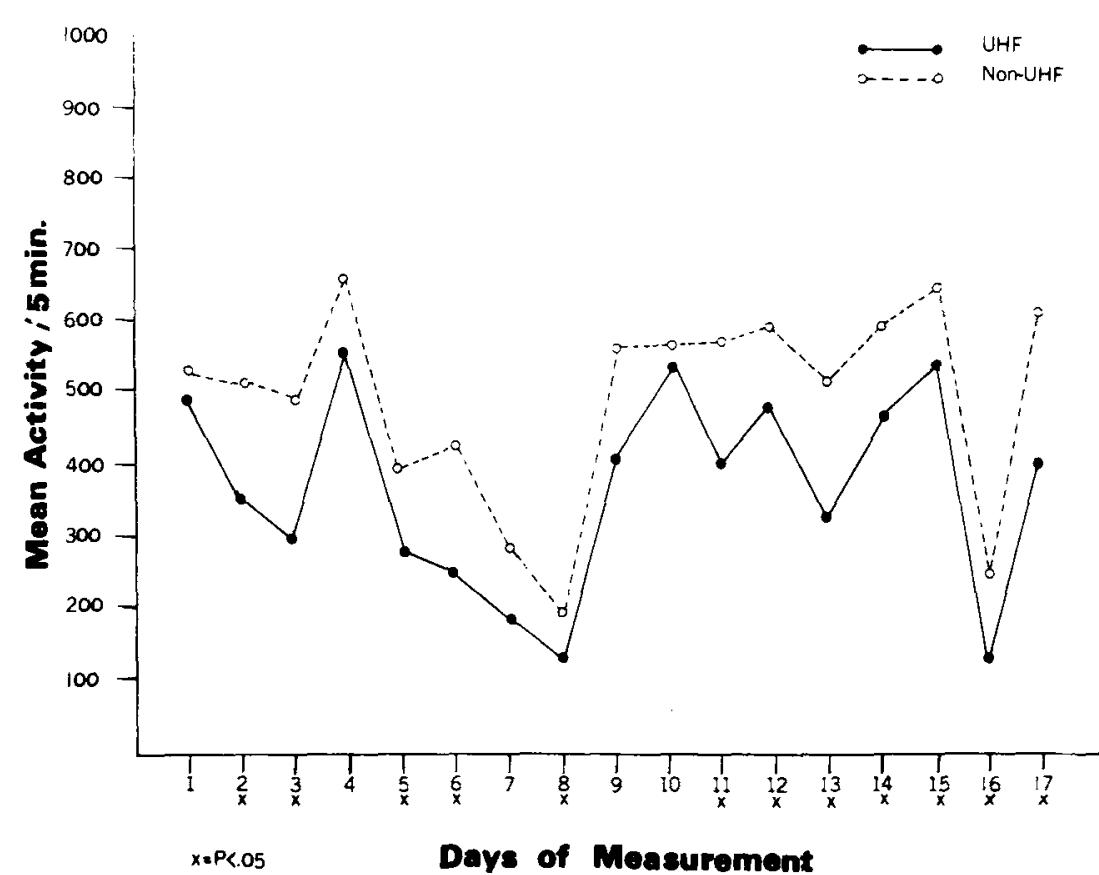

Fig. 1. Mean activity during days of UHF exposure.

being made, daily radiation exposure was of approximately $201 / 2 \mathrm{~h}$ duration. For Days 39-55, UHF was not presented to the experimental Ss.

Beginning on the fifth day of radiation, the activity of the experimental Ss was compared to 15 control Ss, each activity measurement being of $5 \mathrm{~min}$ duration. The order in which the Ss were run was random, as determined by the table of random numbers. For Days 5-38, an activity measure was made every other day with the one exception of a 2-day interval between measurements due to mechanical difficulties with the activity platform. For Days 39-55, i.e., those days when UHF was not presented, activity measures were made daily.

\section{RESULTS}

The Mann-Whitney $U$ test was applied to each day of activity measurement. Of the 17 days of measurement made when UHF was applied (see Fig. 1), all but 5 days were statistically significant (range of significant one-tail $U$ values $=34-72$; $\mathrm{p} \leqslant .05)$, the UHF rats being significantly less active than nonUHF rats. In addition, more significant differences between groups were found as days of radiation increased. For the 17 postUHF measurements (see Fig. 2), the UHF rats were significantly less active than the nonUHF rats on 3 of the first 10 days (range of significant one-tail $U$ values $=$ $51.63 ; p<.05)$. From postUHF Days $11-17$, the activity of the UHF group required for the UHF to have a consistent effect on activity.

The postUHF findings suggest that aftereffects are present, since radiated Ss continued to be hypoactive for a short period of time. However, further investigations of aftereffects are called for, particularly along two lines. First, it is apparent that a study is needed in which UHF is applied for a longer period of time, in order to determine if aftereffects would become more predominant. Secondly, further exploration of aftereffects might prove to be helpful in interpreting the finding that the radiated rats were not significantly less active than the nonradiated rats until the fifth day after UHF termination.

In summary, this research indicates that one major effect of low-intensity UHF radiation, hypoactivity, continues to occur for a short period of time after UHF is terminated.

\section{REFERENCES}

KORBEL, S. F. \& FINE, H. L. Effects of low intensity UHF radio fields as a function of frequency. Psychonomic Science, 1967, 9, 527-528

KORBEL, S. F., \& THOMPSON, W. D Effects of microwave radiation on activity level of rats. Psychological Reports, 1962, 11, 192.

KORBEL, S. F., \& THOMPSON, W. D Behavioral effects of stimulation by UHF radio tields. Psychological Reports, 1965 , 17, 595-602.

KORBEL, S. F. Behavioral effects from UHF exposure. In S. F. Cleary (Ed.), Biological effects and health implications of microwave radiation. Washington: United States Government Printing Office, 1970. Pp. 180-184. also substantiate previous findings of duration effects, in that some time is

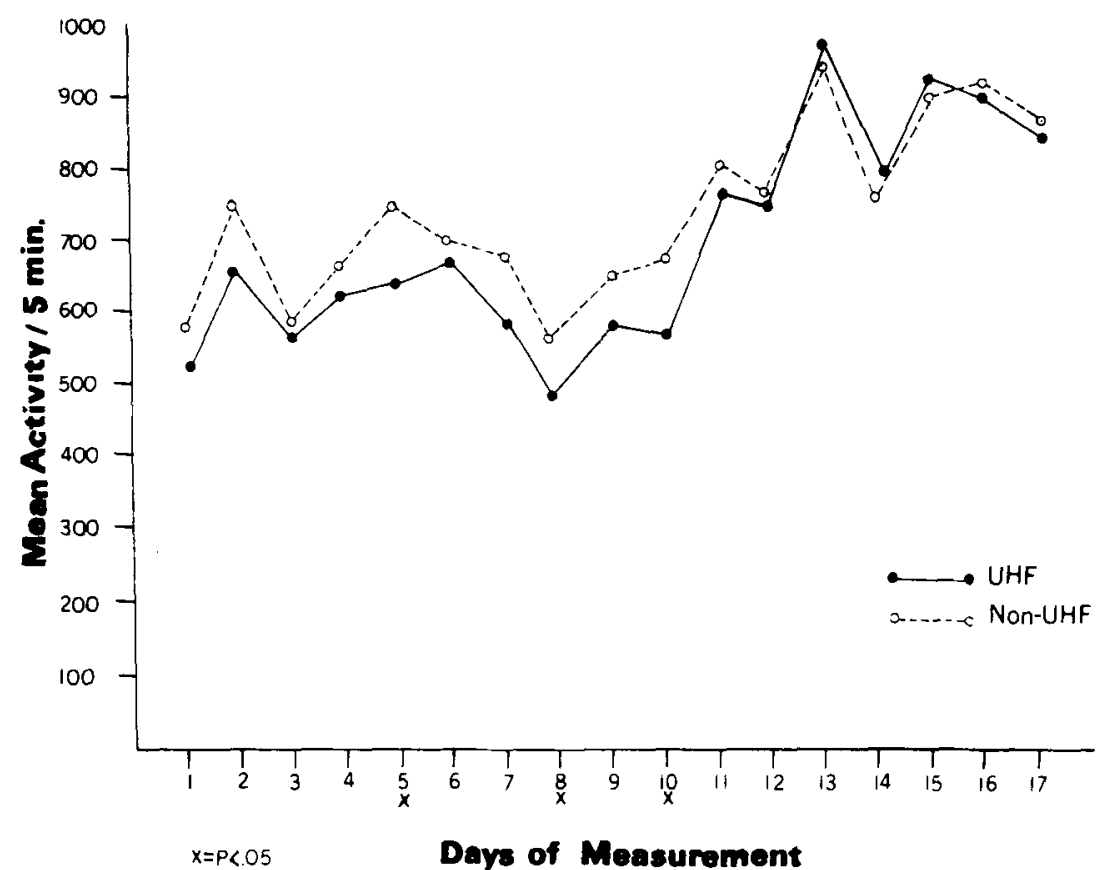

Fig. 2. Mean activity after UHF termination. 